\title{
Construction of an "Industry-dominated" Practical Teaching Mode for Engineering Courses
}

\author{
Lei Bai \\ Engineering Training Center, Beihua University, Jilin, China
}

Keywords: Industry-Dominated; Engineering Practice; Teaching Mode Construction.

\begin{abstract}
The paper proposes an "industry-dominated" practical teaching mode for engineering courses in a bid to obtain talent and intellectual supports of enterprises. It introduces the origin of the teaching mode, constructs the new engineering practical teaching system and relevant courses, points out the importance of engineering awareness cultivation, and elaborates the "industry-dominated" teaching mechanism and base construction scheme.
\end{abstract}

\section{Introduction}

Since its foundation in 1906 by Herman Schneider, the dean of the Engineering School of University of Cincinnati in the United States, cooperative education has had a history of over 100 years. "Industry-dominated" teaching, one mode of university-enterprise cooperation, plays the significant role in education[1-3]. Closely combining practical teaching and industrial demand not only adapts to the needs of application-oriented undergraduate talent cultivation, but also remarkably enhances teaching level and scientific research capability of practice teachers, which is conducive to the industrialization of engineering technologies. Inviting industrial authoritative experts to participate in practical teaching is helpful for the comprehensive reform of practice courses in teaching idea, teaching method, teaching content, and teaching management, the cultivation of application-oriented talents, and students' objective awareness of industrial market and establishment of correct employment goals[4].

\section{Introduction of "industry-dominated" mode}

The teaching mode of university-enterprise cooperation is applied to practical teaching. On the one hand, based on industrial demands and standards, practice courses far lagging behind industrial markets are upgraded in an all-round way; on the other hand, industrial experts are invited to deliver lectures so as to achieve the reasonable transformation of technological theories - technological practice - technological industry. The mode is studied and practiced to find an effective approach more suitable for application-oriented engineering practice teaching, form a new teaching theory, and apply the theory to the actual teaching.

\section{Construction of the new engineering practice teaching system}

Move modern production equipment into the classroom of practice teaching; make industrial authoritative experts instructors in practice teaching; and bring the latest production technologies into practice teaching; the purpose is to create the authentic practice environment for students, and help them acquire more industrial knowledge and more practical skills[5].

The block diagram of the engineering practice teaching system constructed in the paper is shown as Figure 1. With industrial demands as the orientation, the author thoroughly and meticulously investigates and surveys the status and demands of industrial markets, and obtains authentic and objective information and data. With industrial technological experts as the guide, the author combines industrial demands and engineering practice teaching, carries out comprehensive reform in 
teaching idea, teaching document, teaching method, and teaching content, and applies them to practice. After the repeated practice, summarization, and improvement, a set of new teaching theories are formed, and applied to actual teaching effectively.

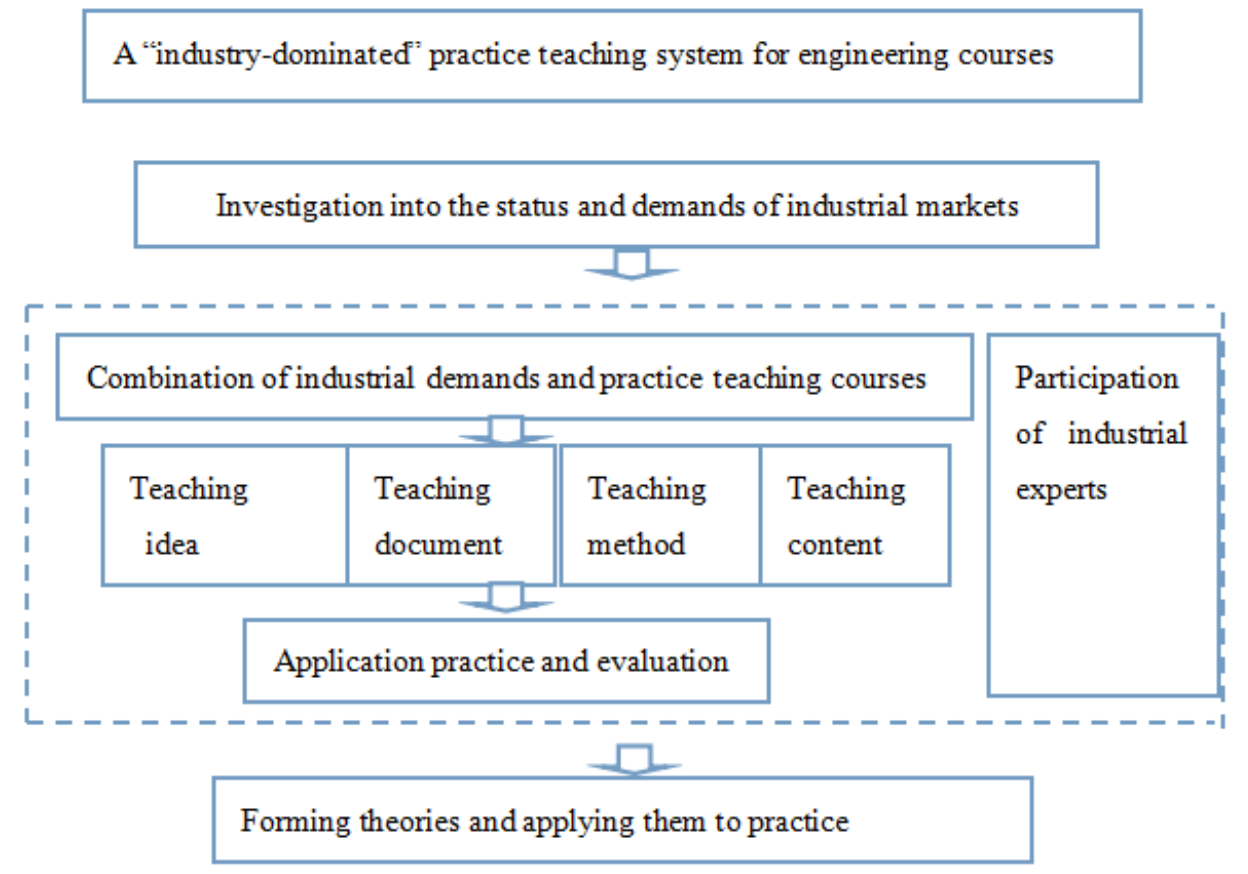

Figure 1 Block Diagram of the System

\section{Construction of engineering awareness}

Practice courses are offered with the participation of industrial technological experts. In the simulated environment of modern production lines, students can quickly move into the role and become members of an enterprise. Practice contents are closely combined with engineering projects to cultivate students' engineering quality, enhance their engineering awareness, and strengthen their engineering practice capability. Through training, students can quickly convert theoretical knowledge learned in books into practical skills, form a kind of engineering thinking mode, and greatly heighten their abilities to learn and solve problems by themselves.

\section{Construction of practice courses linked with industrial production}

The system constructs practice courses with manufacturing products as the carrier, and prepares various teaching documents revolving around product quality, scientific and technological innovation, technical process, and market demand. In terms of practice examination standard, it inspires students' innovative thinking by stressing the process and disregarding the result. Students will not stick to outdated visions since the result of exam just accounts for a small proportion of the final mark. The final mark mainly depends on product design idea, manufacturing difficulty, and practice attitude. Students are allowed to finish contents via network such as course selection, previewing, exercise, test, record, Q\&A, interaction, etc.

\section{Construction of industry-dominated mechanism}

Shown as Figure 2, industrial technological experts, under the "industry-dominated" practice teaching mode, not only are instructors of practice courses, but also help students finish graduation project, course design, innovating \& pioneering training, discipline contest, and employment guidance. Meanwhile, teachers can take part in production skill trainings organized by cooperative enterprises so as to upgrade and enrich their professional knowledge. Universities can sign long-term 
cooperative agreements with enterprises, paying fees to enterprises and formulating rigorous industrial expert employment rules.

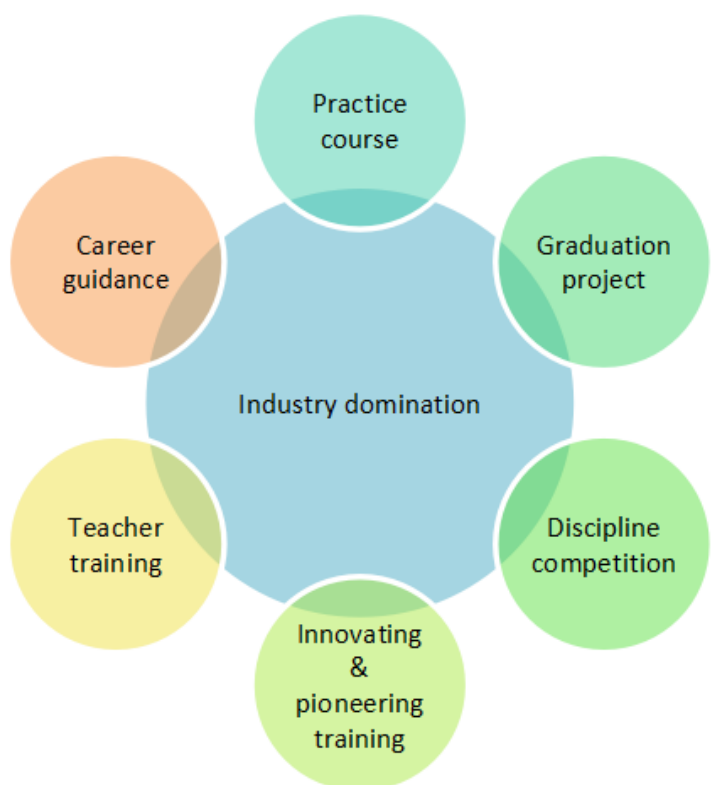

Figure 2 Industry-dominated Mode

\section{Construction of practice bases}

Hardware conditions and soft environment of practice bases are the key to building a new practice teaching mode. Professional software, instruments, and tools used in practice teaching should be upgraded in synchronization with enterprises. In the construction of software environment, attention should also be paid to the display of rules and regulations as well as publicity posters in addition to a simulated environment of actual production lines.

\section{References}

[1]Tan Yanbin. Construction of Practice Teaching System for School and Enterprises[J]. Research \& Exploration in Laboratory, 2015, 34(02):238-242.

[2] Duan Xiaohuan, Yan Wei, Zhang Shihui. Taking School-enterprise Cooperation as A Platform and Building A Work-study Combination Talents Training Scheme[J]. Experimental Technology \& Management, 2014, 33(04):134-138.

[3] Wang Pingxiang. Reflections on Deepening Talent Training Mode and Innovating Test Site Construction[J]. China University Teaching, 2015 (03):74-77.

[4] Sun Hao, Li Hui. Exploration into and Practice of the Cultivating Engineering University Students' Innovative Practice Capability[J]. China University Teaching, 2015(04):77-80.

[5] Wei Jia, Ni Jie, Wu Yuanzheng. Construction of Practical Teaching System for Application-oriented Undergraduate Based on Professional Ability Training[J]. Experimental Technology \& Management, 2015, 32(03):207-209. 